\title{
DOES LAMINAR POSITION DETERMINE THE RECEPTIVE FIELD PROPERTIES OF CORTICAL NEURONS? A STUDY OF CORTICOTECTAL CELLS IN AREA 17 OF THE NORMAL MOUSE AND THE REELER MUTAN'T ${ }^{1}$
}

\author{
VANCE LEMMON AND ALAN L. PEARLMAN ${ }^{2}$
}

Department of Physiology and Biophysics, and Department of Neurology and Neurological Surgery, Washington University School of Medicine, St. Louis, Missouri 63110

\begin{abstract}
The neocortex of the reeler $(r l)$ mutant mouse develops abnormally; as a result, the orderly arrangement of cells in laminae containing neurons of similar size and configuration is severely disrupted. The reeler mutant thus offers an opportunity to study the role played by laminar position in establishing the interneuronal connections of the cortex. Since the receptive field properties of neurons in the primary visual cortex (area 17) are determined by these complex interconnections, a study of receptive field properties provides a useful way to test whether functionally important connections are altered by abnormal cell position. We chose the corticotectal (CT) cells of area 17 for this analysis because they have distinctive receptive field properties and can be identified positively by antidromic stimulation with electrodes in the superior colliculus. In addition, CT cells are located in a single lamina (layer V) in the visual cortex of normal mice, but are distributed from surface to white matter in the reeler visual cortex. We characterized the receptive fields of identified CT cells in area 17 of normal mice and reeler mutants and studied several properties of these cells quantitatively. Corticotectal cells in the visual cortex of the normal mouse have high rates of spontaneous activity and large receptive fields that are neither oriented nor directional; they respond to moving stimuli over a wide range of stimulus velocities, have high peak velocity sensitivities, and show very little spatial summation. Corticotectal cells in the visual cortex of the reeler mutant do not differ significantly in these characteristics, although CT cells with extremely large receptive fields are encountered somewhat more frequently in reeler cortex. These findings indicate that the detailed connections which determine the receptive field properties of CT cells are properly established in the reeler mutant mouse despite the markedly abnormal positions of CT cells in reeler visual cortex.
\end{abstract}

The mammalian neocortex is a distinctly laminated structure, characterized by layers of neuronal cell bodies of similar size and configuration separated by zones that are relatively cell-free but filled with interconnecting neuronal processes. From one region of neocortex to another, the laminae differ in the size, number, and packing density of the neurons that they contain; these differences were used by neuroanatomists at the turn of

\footnotetext{
'This work was supported by National Institutes of Health Research Grant R01-EY00621 from the National Eye Institute. V. Lemmon received support from National Institutes of Health Training Grant T01-EY00092 from the National Eye Institute. We are very grateful to Dr. Verne Caviness for many helpful suggestions and for providing reeler mice used in preliminary experiments, to Elaine Siegfried and Randy Rader for technical assistance, and to Jan Wuelling and Sue Eads for typing the manuscript. A portion of this work was reported earlier in abstract form (Lemmon and Yearlman, 1979a, b).

${ }^{2}$ To whom reprint requests should be addressed at Washington University School of Medicine, 660 South Euclid, St. Louis, MO 63110.
}

the century to subdivide the cortex into cytoarchitectonic regions (Brodmann, 1903; Campbell, 1903; Vogt, 1903). Although the full functional significance of cortical lamination is far from understood, the list of anatomical and physiological features that characterize and distinguish cortical laminae continues to grow. In the primary visual cortex, for example, terminals of afferents from the lateral geniculate nucleus are not only restricted to specific laminae, but are limited to particular zones within laminae depending on the geniculate layer where they arise (Hubel and Wiesel, 1972; LeVay and Gilbert, 1976; Ferster and LeVay, 1978; Leventhal, 1979). Afferents from the pulvinar (Carey et al., 1979) and from other cortical regions (Tigges et al., 1977) are also distributed to particular cortical layers, and the pyramidal neurons of the individual layers have distinct sites of projection (Hollander, 1974; Gilbert and Kelly, 1975; Lund et al., 1979).

The functional properties of neurons in area 17 also differ depending on the cortical layer where the cell body lies (Hubel and Wiesel, 1962, 1968; Kelly and Van Essen, 
1974; Palmer and Rosenquist, 1974; Toyama et al., 1974; Camarada and Rizzolatti, 1976; Schiller et al., 1976; Maffei and Fiorentini, 1977; Gilbert, 1977; Gilbert and Wiesel, 1979; Leventhal and Hirsch, 1978; Mangini and Pearlman, 1980). Cells with specific receptive field characteristics tend to predominate in particular cortical layers, although in many instances, the distinctions between cortical laminae are not sharp. It should be emphasized in this context that the dendritic and axonal arborizations of many neurons are not limited to a single cortical layer but rather extend vertically to interconnect cortical laminae in ways that are apparently specific to the cells of each layer (Lund et al., 1979; Gilbert and Wiesel, 1979). A further distinction between the layers of the neocortex is evident during the early stages of development. Cells that will eventually take up positions in the deep cortical layers are the first to undergo their final cell division in the proliferative zone near the ventricle, and those that will finally reside in the most superficial layers are the last to be formed (Angevine and Sidman, 1961; Caviness and Sidman, 1973; Rakic, 1974).

Given this substantial and growing list of anatomical, physiological, and developmental features that are correlated with the laminar structure of the neocortex, one might reasonably ask whether cortical lamination plays a role in the development of the neuronal interconnections that determine cortical function. Simply put, is the laminar position of the cell body of an individual cortical neuron an important determinant of the connections it will receive? The reeler mutation in the mouse appears to be a model in which this problem can be studied, since the most striking abnormality in the neocortex of this mutant is incorrect positioning of the cell bodies of neocortical neurons. The mutation also affects other laminated cortical structures (hippocampus and cerebellum), but apparently spares subcortical structures.

All major classes of cells are present in the neocortex of the reeler mouse and the cell classes are segregated at various cortical levels, but the borders between classes are not distinct. The polymorphic neurons that normally form layer VI are found immediately beneath the pia in reeler, taking the place of the molecular layer. There is also an inversion of the relative positions of pyramidal cells. Normally the medium and small pyramidal cells are found in the superficial cortical layers (layers II and III) and large pyramidal cells occur deep in the cortex (layer V). In reeler, pyramidal cells lie in a broad band extending from just beneath the superficial layer of polymorphic cells inward to the white matter. The largest pyramidal cells are found primarily in the outer half of this band, while the medium and small cells are mainly deep in the cortex (Caviness, 1976a). The stellate cells that characterize the midcortical zone in the normal mouse are found in similar positions in the reeler, but are less densely packed, overlapping the large pyramidal cells above and the medium and small cells below (Caviness, 1976a). Autoradiographic labeling of embryonic cells with $\left[{ }^{3} \mathrm{H}\right\rceil$ thymidine has demonstrated that the various cell classes of reeler neocortex are generated in the normal sequence, but come to lie in an inverted relationship to each other in the cortex (Caviness and Sidman, 1973).
A number of neuroanatomical studies have addressed the question of whether the abnormality in cell position in the neocortex of reeler mutant alters the formation of neuronal interconnections. Thalamocortical and callosal afferents terminate among the appropriate cortical neurons, even though these neurons are in abnormal positions (Frost and Caviness, 1974; Caviness, 1975, 1976a; Steindler and Colwell, 1976). Similarly, in the hippocampal formation of reeler, the principal afferents are distributed in a manner that is like that in normal mice in most respects, even though many of the neurons of origin and the target neurons are abnormally located (Stanfield et al., 1979). There are, however, some significant abnormalities in the zones of distribution of afferents and indications that, in some cases, afferent terminations may occur on the proper cells but in abnormal locations on those cells (Stanfield and Cowan, 1979a, b). In the cerebellum of reeler, many Purkinje cells are located deep in the cerebellum instead of in the cortex, and the number of granule cells is significantly reduced. Many of the neurons in the cerebellum establish normal synaptic connections, but there is also evidence for abnormalities in the number, location, and specificity of connections (Rakic, 1976; Mariani et al., 1977).

Since the receptive field characteristics of neurons in the visual cortex are determined by a complex array of cell-to-cell interconnections, an analysis of receptive fields should indicate whether connections are altered by abnormal cell position. Drager (1975b, 1977), who first recorded from area 17 in reeler, has provided preliminary reports which indicate that cells with normal-appearing receptive fields are present in reeler cortex; since the neurons being studied were not identified, it is difficult to know whether the receptive field characteristics described were appropriate for those cells. In order to approach this question, it would be best to select a cortical cell population that (1) normally lies within a restricted laminar zone of cortex, but is abnormally located in reeler cortex; (2) has distinctive receptive field properties that represent the outcome of interactions within the cortex; and (3) can be positively identified during electrophysiological experiments in the normal mouse and the reeler mutant.

An analysis of the laminar distribution of the receptive field properties of neurons in area 17 of the mouse, carried out in this laboratory, has characterized a class of cells that satisfies these conditions (Mangini and Pearlman, 1980). These neurons, called large field, non-oriented (LFNO) cells, are restricted to layer $\mathrm{V}$ and have receptive field properties that distinguish them from other cortical neurons. Preliminary experiments indicated that some LFNO cells can be activated by antidromic stimulation of the superior colliculus and thus are corticotectal neurons. Injections of horseradish peroxidase into the superior colliculus demonstrated that the corticotectal cells of area 17 in the normal mouse are restricted to layer V (Mangini and Pearlman, 1980); in contrast, corticotectal cells in the reeler are distributed from surface to white matter and therefore are positioned quite abnormally (Caviness, 1977; N. J. Mangini, V. Lemmon, and A. L. Pearlman, unpublished observations).

In the present study, we analyzed neurons in area 17 
of the normal mouse and the reeler mutant that were identified as corticotectal cells by antidromic stimulation. We examined receptive field size, spontaneous activity, velocity sensitivity, and spatial summation to determine whether the connections that underlie these functional properties are established in the reeler, despite the abnormality in cell position that characterizes the mutant neocortex.

\section{Materials and Methods}

The receptive field properties of corticotectal (CT) cells in area 17 were studied in $16 \mathrm{C} 57 \mathrm{BL} / 6 \mathrm{~J}$ mice (normal mice) and in nine $\mathrm{C} 57 \mathrm{BL} / 6 \mathrm{~J} \mathrm{X} \mathrm{C3H}$ hybrid mice that were homozygous for the reeler $(r l)$ mutation. Both the normal mice and the breeders used to produce the homozygous reeler mice were obtained from Jackson Laboratory, Bar Harbor, ME. The unaffected littermates of the reeler mice were not used as the normal control animals because the C57BL/6J X C3H $\mathrm{rl} /+$ breeders from Jackson Laboratory also carry the gene for retinal degeneration $(r d)$. Reeler mice with retinal degeneration were also eliminated from the study.

The details of the anesthesia, surgery, and recording techniques have been provided elsewhere (Wagor et al., 1980; Mangini and Pearlman, 1980). In brief, mice ranging in age from 10 weeks to 6 months were preireated with atropine $(1.1 \mathrm{mg} / \mathrm{kg})$ and anesthetized with urethane $(2.24 \mathrm{gm} / \mathrm{kg})$. Neuromuscular blocking agents were not used to paralyze the animals since eye movements are not a significant problem in the anesthetized mouse (Drager, 1975a; Mangini and Pearlman, 1980). The posterior half of the left parietal bone and most of the interparietal bone were removed, exposing the posterior aspect of the left hemisphere and the midbrain.

Two glass-insulated tungsten electrodes $(75-\mu \mathrm{m}$ exposed tip) were placed in the superficial gray of the left superior colliculus in a parasagittal plane at an angle $54^{\circ}$ from the vertical. Then, the positions of the electrodes and their relation to the map of the visual field on the superior colliculus were determined by recording the multi-unit activity evoked by projecting visual stimuli onto a hemisphere situated to cover most of the right visual field. Electrode placements were restricted to the posterior aspect of the superior colliculus to avoid disrupting either the transverse sinus or the posterior neocortex; as a consequence, only that part of the superior colliculus that represents the temporal half of the visual field was available for study. The two electrodes then were connected to a stimulator (W-P Instruments, model $302-\mathrm{T})$ to provide bipolar stimulation of the superior colliculus. Stimuli consisted of monophasic, constant current pulses ( $200 \mathrm{msec}, 0.05$ to $0.5 \mathrm{~mA}$ ). Current values were monitored with an $\mathrm{AC}$ current probe (HewlettPackard 546A).

Cells in area 17 were studied with standard extracellular, single unit recording techniques. Corticotectal (CT) cells in area 17 were isolated by slowly advancing the cortical microelectrode while the superior colliculus was being stimulated electrically. A cell was judged to be antidromically activated if it followed a burst of 5 stimuli $(180 / \mathrm{sec})$ with latencies that did not vary by more than

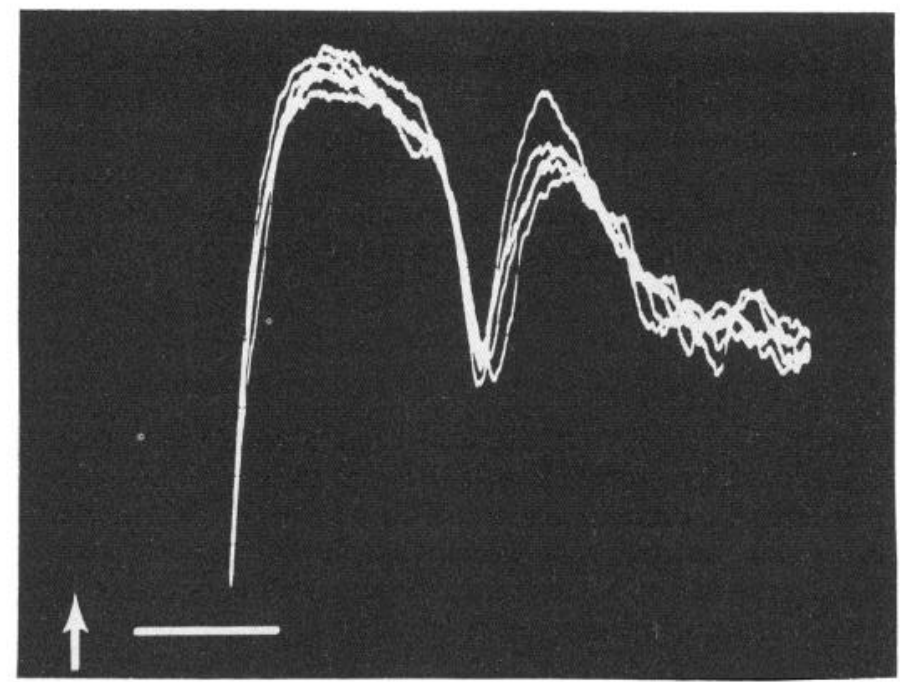

Figure 1. Example of antidromic activation of a CT cell by stimulating electrodes in the superior colliculus. This CT cell followed a $180-\mathrm{Hz}$ burst of five stimuli with a constant latency. Oscilloscope tracings of the five responses are superimposed. The arrow indicates the time of stimulation; the horizontal bar represents $1 \mathrm{msec}$. The large deflection above the horizontal bar is the stimulus artifact.

$0.2 \mathrm{msec}$ (Fig. 1). In many instances, antidromic activation of a cell was confirmed by collision; spontaneously occurring action potentials that occurred shortly before electrical stimulation of the superior colliculus resulted in the failure of the stimulation to produce an action potential. Collision testing was routinely carried out if the cell's response latency to antidromic stimulation was longer than $4.5 \mathrm{msec}$.

Each CT cell's receptive field properties were examined qualitatively by back-projecting stimuli from a hand-guided projector onto a tangent screen $28 \mathrm{~cm}$ from the mouse's right eye. Receptive field size was determined by mapping the maximum excitatory response field with small $\left(5^{\circ}\right)$ moving stimuli. Receptive field sizes were corrected for the distortion produced by plotting on a flat screen (Drager and Hubel, 1975); size was defined as width + height/2. Means were compared by a twosided $t$ test $(\alpha=0.05 \%)$. An automated system, including a LINC computer, was used to present stimuli and record responses for quantitative studies of receptive field properties. Flashing stimuli were produced by an electronic shutter; moving stimuli were produced with a mirror mounted on a pen-motor galvanometer. Data were collected in the form of peri-stimulus time histograms (500 bins, 10 -msec bin width). Usually 10 stimulus presentations were used to generate responses for each histogram.

Small lesions were made at the sites where most of the CT cells were recorded by passing current $(2 \mu \mathrm{A}, 4 \mathrm{sec}$, electrode negative) through the cortical microelectrode. At the end of the recording session, the mouse was given an additional large dose of anesthesia (methohexital sodium, $625 \mathrm{mg} / \mathrm{kg}$ ) and perfused through the heart with saline followed by $10 \%$ formalin. The brain was then removed and processed for frozen sectioning and thionine staining. 


\section{Results}

\section{Qualitative analysis of receptive characteristics}

All of the cells on which we report in this study were identified as corticotectal (CT) cells by electrical stimulation of their axons in the superior colliculus. Receptive field characteristics examined qualitatively included responses to stationary flashing stimuli, responses to moving bars and edges of various orientations and directions, and preferences for moving light and dark edges. Most CT cells in area 17 of both normal and reeler mice had on-off responses to stationary flashing stimuli throughout their receptive fields. On responses were generally stronger than off responses. CT cells responded vigorously to moving bars regardless of orientation or direction of movement; both light and dark edges were effective stimuli. Extending the stimulus beyond the excitatory region of the receptive field did not produce significant inhibitory effects. In a few cells, the preference for small light or dark bars of equal contrast with respect to the background was examined; these cells responded better to light bars on dark backgrounds.

The location of a CT cell's receptive field in the visual field could be accurately predicted from the location of the stimulating electrodes in the superior colliculus and their relation to the map of the visual field on the superior colliculus. Receptive fields of CT cells were always within $25^{\circ}$ of the receptive field of the multi-unit activity recorded from one of the stimulating electrodes. Placement of the stimulating electrodes more anteriorly in the colliculus changed the location of the cortical area that was activated in a manner predicted by the retinotopic organization, but did not result in activation of CT cells over a larger area of the visual cortex. This suggests that corticotectal axons proceeding to more posterior portions of the colliculus in the stratum opticum were not activated by current spread from the stimulating electrodes.

Receptive field size. Receptive fields of both normal and reeler CT cells were very large; the means $\left(66.5^{\circ}\right.$ for normal mice and $72.8^{\circ}$ for reeler mice) (Fig. 2) were not significantly different. Although the means did not differ, Figure 2 indicates that the distribution of receptive field sizes for reeler CT cells may be bimodal. Ten of the 26 CT cells studied in reeler had receptive fields that were $90^{\circ}$ to $100^{\circ}$, while only two of the $41 \mathrm{CT}$ cells from normal mice were that large. Since Drager (1977) found some cells in the reeler visual cortex that were superficial and had very large receptive fields, we were interested in whether there was a correlation between depth from the cortical surface and CT cell receptive field size. If, for example, the CT cells that were most superficial, i.e., farthest from their "normal" location, had the largest receptive fields, one should observe such a correlation and perhaps a bimodal distribution of receptive field sizes as well. Instead, we found that CT cells with very large fields were distributed throughout the cortex in reeler and that there was no correlation between receptive field size and depth from the cortical surface (correlation coefficient, 0.07).

The receptive field sizes of the large field, non-oriented (LFNO) cells in layer V of area 17 in the normal mouse have been shown to vary with position in the visual field (Mangini and Pearlman, 1980). With progression from nasal to temporal in the nasal half of the field, LFNO receptive fields gradually increase in size; no additional increase occurs with progression through the temporal half of the visual field. As a consequence, it is important to be certain that the populations of CT cells studied in normal and reeler visual cortex were from similar parts of the visual field; Figure 3 indicates that the azimuth locations of the receptive fields were quite similar. Since only the posterior one-third to one-half of the colliculus was accessible to the stimulating electrodes, only CT cells with receptive fields in the temporal half of the visual field were available for study. Like the receptive fields of LFNO cells, CT cells of normal and reeler mice with receptive fields in the temporal half of the visual field did not increase significantly in receptive field size with nasal-to-temporal progression (Fig. 3). A separate

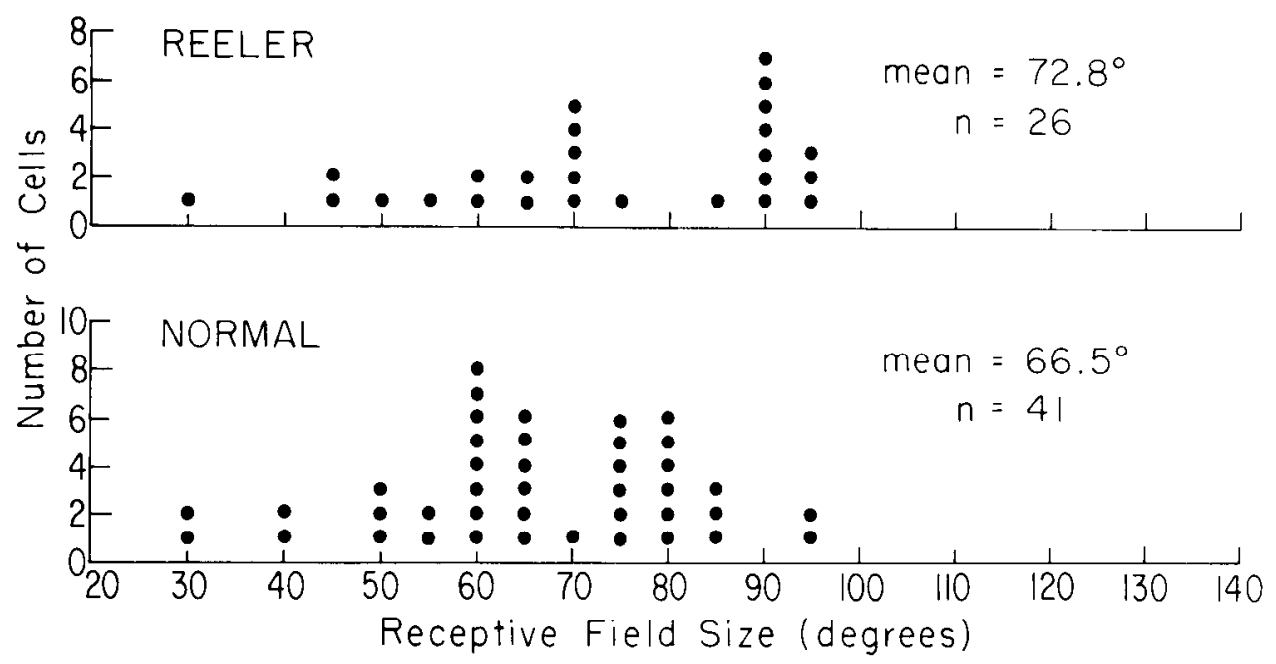

Figure 2. Receptive field size. Although the mean receptive field sizes for CT cells in reeler and normal mice were not significantly different, there is a cluster of cells in reeler cortex with very large fields. 


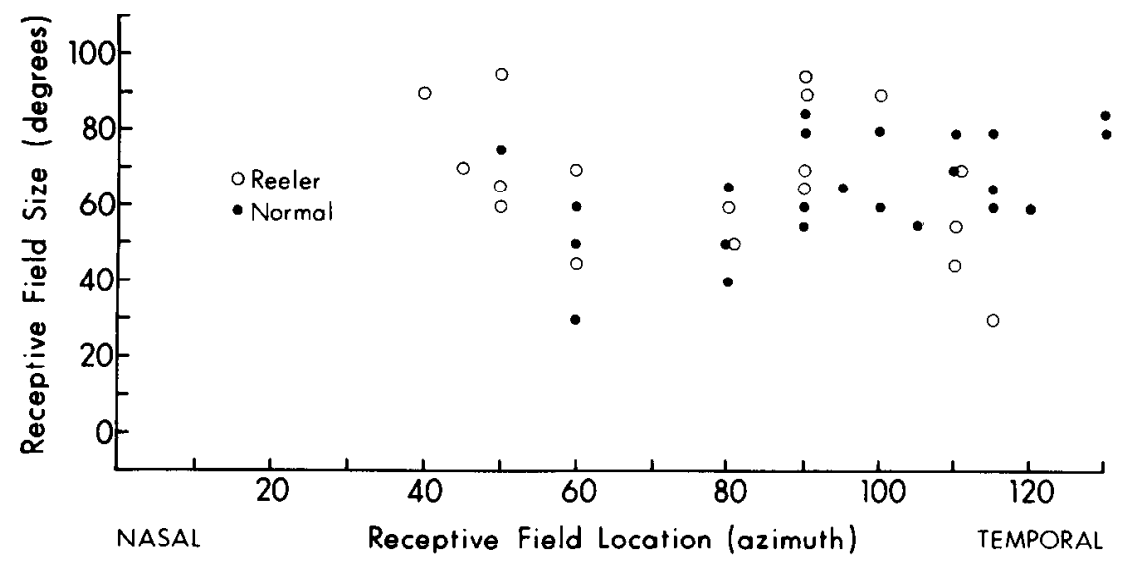

Figure 3. Receptive field size as a function of distance from the vertical meridian. The vertical meridian, or $0^{\circ}$ azimuth line, was defined by the intersection of the midsagittal plane of the mouse's head with the hemisphere used for mapping receptive fields. For this figure, visual field location was defined by a point at the center of each receptive field.

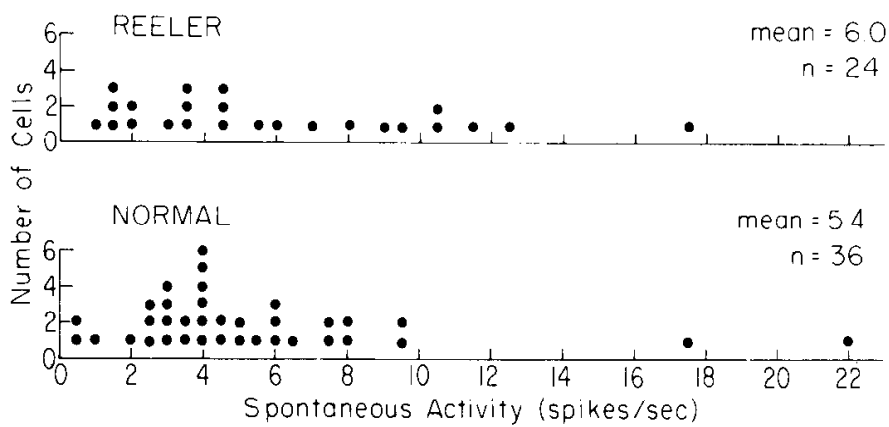

Figure 4. Determinations of spontaneous activity were made by counting the number of spikes during 10 time periods, each $5 \mathrm{sec}$ long. The mean rates of spontaneous activity for CT cells in reeler mice and normal mice were not significantly different.

plot of receptive field elevations as a function of receptive field size also showed that the distribution of the populations sampled in reeler and normal were quite similar and that receptive field size did not vary significantly as a function of elevation.

\section{Quantitative studies of receptive field properties}

Spontaneous activity. CT cells of both normal and reeler mice had high mean rates of spontaneous activity (6.0 and 5.4 spikes/sec respectively, Fig. 4). The ranges of the two sets of data were similar and the means were not significantly different.

Direction and orientation selectivity. Receptive fields of $21 \mathrm{CT}$ cells in normal mice and seven CT cells in reeler mice were studied quantitatively to determine whether they had directionality or orientation specificity that was not apparent in our qualitative studies. For this analysis, and for the determinations of velocity sensitivity and spatial summation which follow, we chose a space-independent measure of response, the maximum firing frequency, that permits comparisons among responses to stimuli that are in the cells receptive field for different durations (Movshon, 1975). CT cells from both normal and reeler mice showed no particular preference for one stimulus orientation over others and the response to a bar moving in any one direction was approximately equal to the responses in the other directions (Fig. 5).

Velocity sensitivity. Corticotectal cells responded to moving stimuli with a wide range of velocities (usually from about $10^{\circ} / \mathrm{sec}$ to over $1000 \% / \mathrm{sec}$ ) and often responded best to rapidly moving stimuli. Figure 6 shows examples of the velocity sensitivity curves obtained from one CT cell in a reeler mouse and one CT cell in a normal mouse. In order to compare the velocity sensitivities of CT cells in reeler and normal mice, we determined the stimulus velocity that produced the highest maximum response frequency (Fig. 6) and used this as an index of peak velocity sensitivity. Figure 7 shows the data resulting from this comparison. The range of peak velocity sensitivities is similar for CT cells in reeler and normal mice and the means $\left(256^{\circ} / \mathrm{sec}\right.$ and $281^{\circ} / \mathrm{sec}$, respectively) are not significantly different.

Spatial summation. The receptive fields of CT cells in area 17 of the cat show very little spatial summation; they are unusual in this regard when compared with other cells in the cat's visual cortex (Palmer and Rosenquist, 1974). We examined CT cells in the visual cortex of mice to determine whether they also lack spatial summation and whether CT cells in normal mice and reeler mutants are similar in this respect. Spatial summation was analyzed by presenting moving bars that had a width of $2^{\circ}$ and lengths varying from $2^{\circ}$ to over $100^{\circ}$; maximum response frequency was plotted as a function of the length of the stimulus. Figure 8 shows examples from one CT cell in a reeler and one CT cell in a normal mouse. The response curves rise very quickly with increasing stimulus length and then level off at stimulus lengths that are well short of the receptive field diameter as determined by plotting the excitatory response fields. Similar curves indicating very little spatial summation were obtained from $12 \mathrm{CT}$ cells in normal mice and 11 $\mathrm{CT}$ cells in reeler mice. In all cases, the response to stimuli $15^{\circ}$ in length was at least half the maximum 


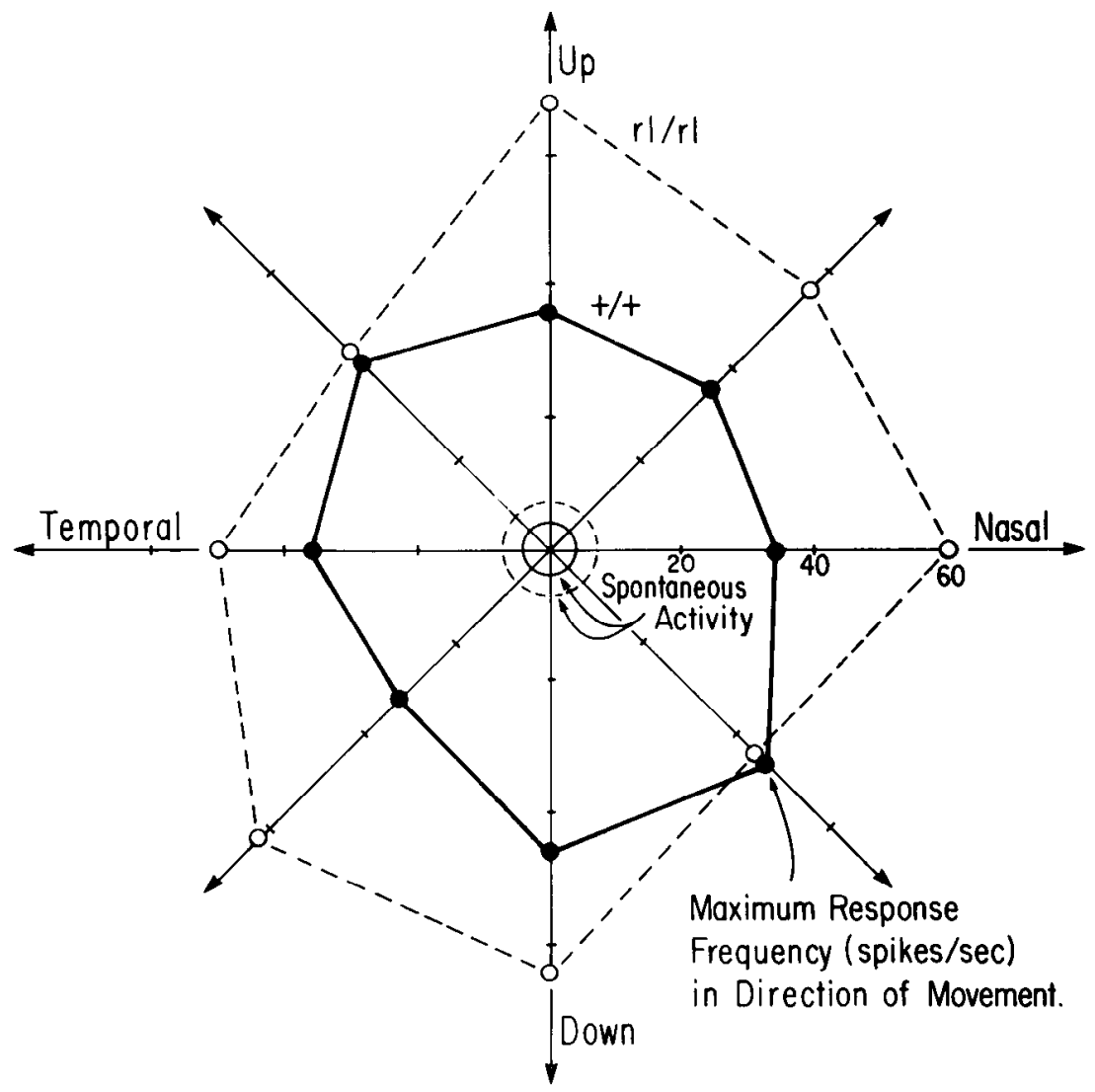

Figure 5. In these polar plots, the distance of a point from the origin represents the maximum response frequency elicited by a bar moving along a given axis in the direction of the arrow. Stimulus bars were oriented perpendicular to the axis of movement. The open circles connected by dashed lines show data from a representative CT cell in a reeler mouse, and the solid circles connected by solid lines show data from a representative CT cell in a normal mouse. In this and subsequent figures, maximum response frequency was calculated by determining the number of spikes generated by the cell during a 50 -msec period centered at the largest part of the response as measured on the peri-stimulus time histogram. The magnitude of each cell's response was approximately the same for all stimulus orientations and directions of movement. It should be noted that the absolute magnitude of responses varied from cell to cell, but this variation was not related to whether the cell was from normal or reeler cortex.

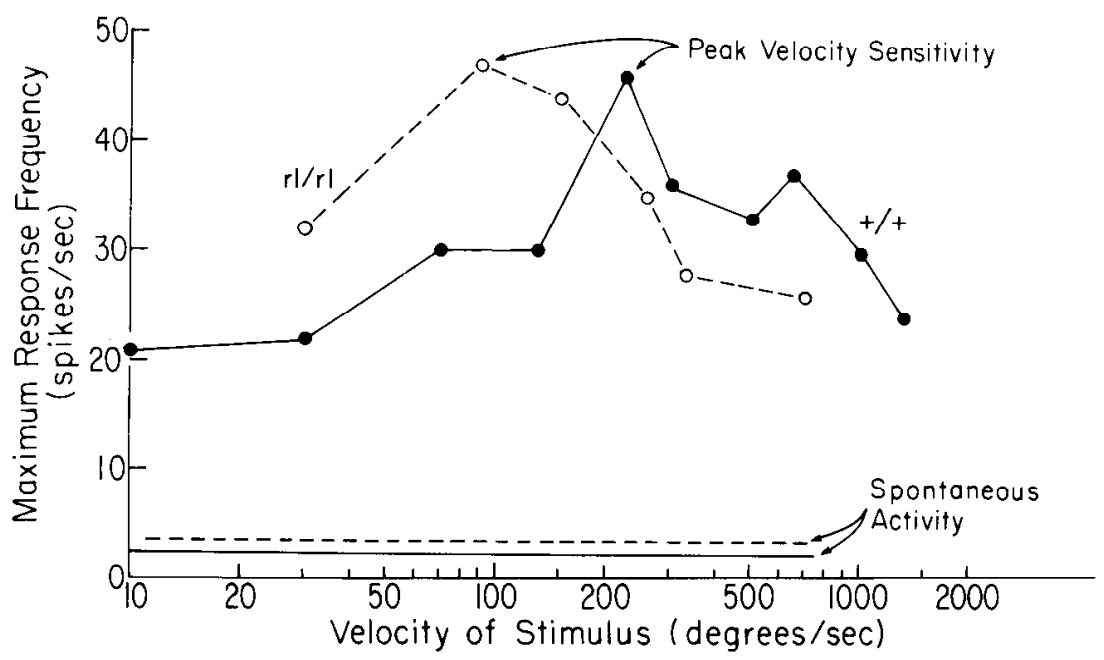

Figure 6. Velocity tuning of CT cells. The open circles are data from a single CT cell in a reeler mouse and the solid circles are from a CT cell in a normal mouse. Dashed and solid straight lines indicate the level of spontaneous activity of each of the cells. 


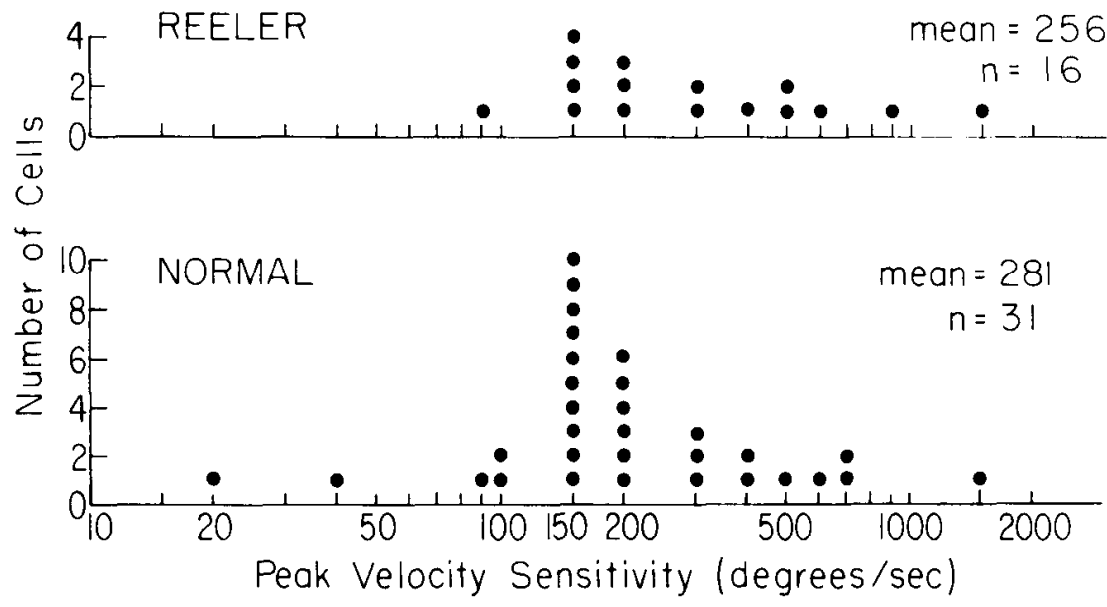

Figure 7. Peak velocity sensitivity was defined as the stimulus speed producing the highest maximum response frequency for a given cell (see Fig. 6). This comparison of peak velocity sensitivities shows a similar range of values for CT cells in reeler and normal mice; the means were not significantly different.

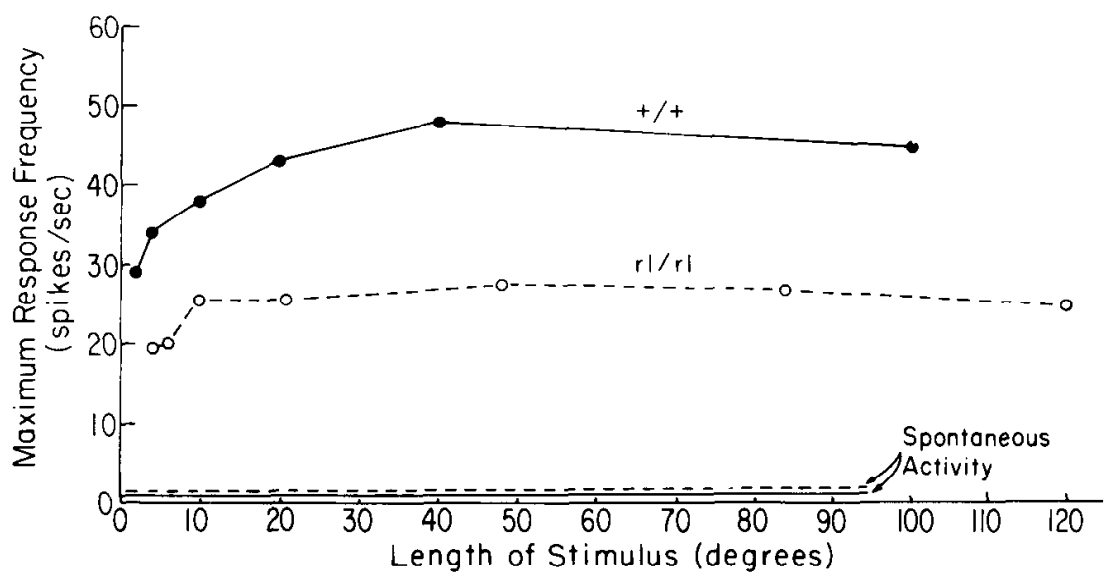

Figure 8. Spatial summation of CT cells was examined with bars of different lengths. The open circles show data from a single CT cell in a reeler that had a receptive field $95^{\circ}$ in diameter and the solid circles show data from a CT cell in a normal mouse with a receptive field $75^{\circ}$ in diameter. Very large increases in stimulus lengths produced relatively small changes in responses from CT cells. As in Figures 5 and 6, the shape of the response curves is considered of primary importance for this analysis, while the magnitude of the responses from one cell to the next is not important in determining whether or not a cell has spatial summation.

response despite the fact that the receptive fields ranged from $40^{\circ}$ to $100^{\circ}$ in diameter.

Location of $C T$ cells. Small electrolytic lesions were placed at most of the sites in the visual cortex where CT cells were recorded. All of the lesions that were placed near CT cells in normal mice were in, or very near, layer $\mathrm{V}$ of area 17 (Fig. 9A). In contrast, lesions placed near CT cells in reeler mice were scattered from immediately beneath the cortical surface (Fig. 9B) to locations near the white matter; the majority were located in the upper half of the visual cortex.

\section{Discussion}

Corticotectal cells. In attempting to assess the role played by laminar position in determining the functional characteristics of cortical neurons, we considered it important to choose a cell population that could be positively identified during physiological recording experiments and whose receptive field properties were characteristic of a particular cortical lamina and distinct from cells in other laminae. Positive identification is necessary since it is conceivable that a given population of malpositioned neurons in reeler cortex might acquire the connections necessary for the receptive field properties that are normal for some class of cells, but not for the population in question. If that were the case, corticotectal cells located in the superficial aspect of the reeler visual cortex might acquire receptive field properties that were like those of the callosal cells that are normally located superficially; sampling a population of unidentified cor- 

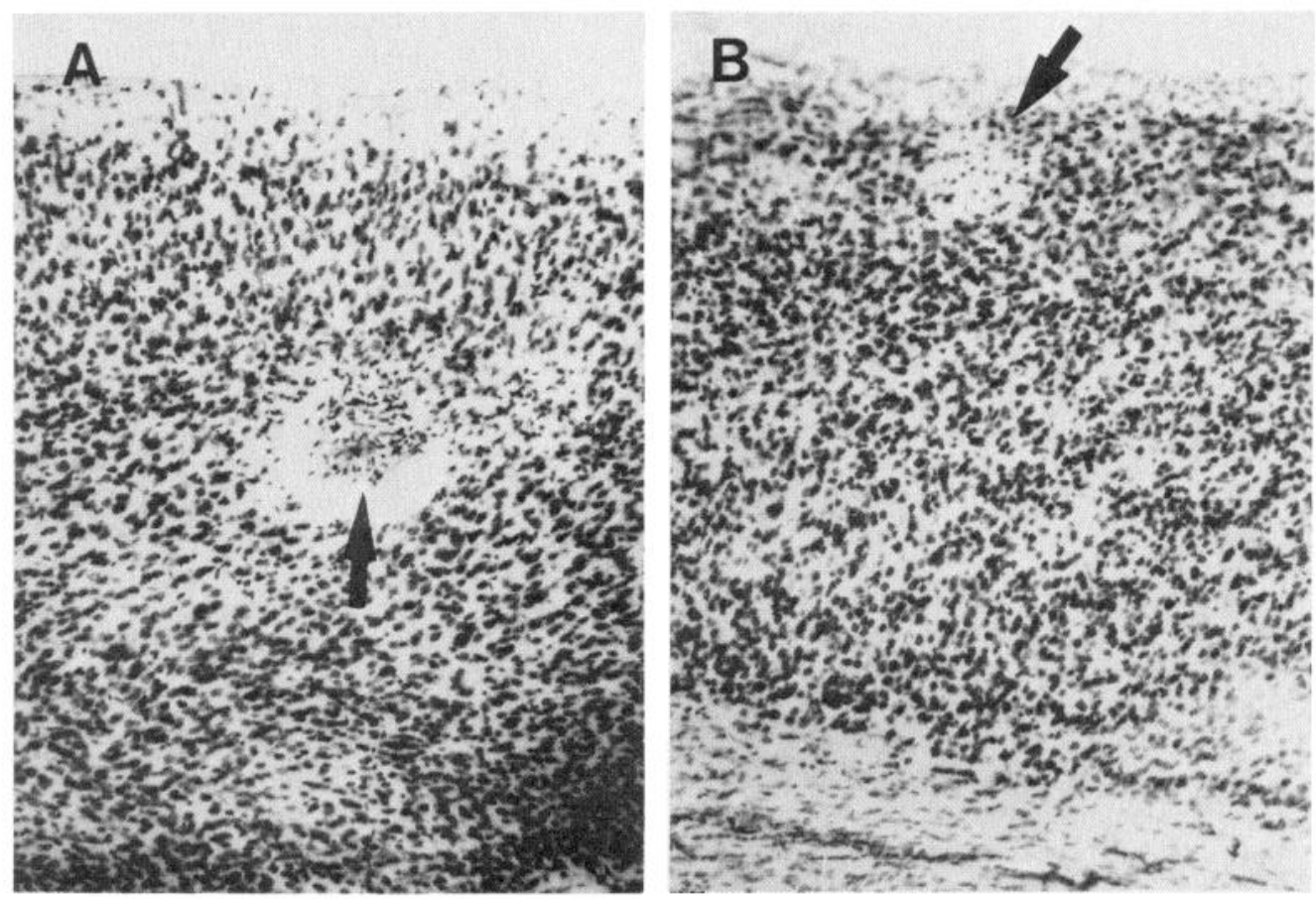

Figure 9. A, Parasagittal section showing a lesion (arrow) in layer V of area 17 in a normal mouse at the recording site of a CT cell. $B$, Parasagittal section showing a lesion (arrow) in the superficial aspect of area 17 in a reeler mouse at the recording site of a CT cell.

tical neurons would not detect this outcome. A population of neurons with distinct, lamina-specific receptive field properties is also necessary to examine the role of cell position, since otherwise it might not be possible to determine that cells had received abnormal connections if the receptive fieid properties that they acquired in abnormal locations were similar to those that they would have acquired in their normal lamina. For example, cells with non-oriented receptive fields are found in all cortical layers in the normal mouse, although they are most prevalent in layer IV (Mangini and Pearlman, 1980). If a neuron normally destined to have a non-oriented receptive field and reside in layer III ended up deep in the cortex and if its connections were determined by its cortical location, it might still have a non-oriented receptive field even though it had not received its normal connections.

In choosing the neuronal population for study in these experiments, we were guided by the two studies of receptive field properties of neurons in area 17 of the mouse published to date (Drager, 1975a; Mangini and Pearlman, 1980). These studies are sufficiently detailed and include enough cells (over 600 in combination) that it seems likely that the major classes of cells present in the primary visual cortex of the mouse have been identified. There is fairly good agreement between these two studies as to the classes of receptive field types present and their relative proportions. Between 35 and $45 \%$ of the cells in the visual cortex of the mouse have oriented receptive fields that can be classified as simple or complex; the remainder have non-oriented receptive fields. Between 50 and $70 \%$ of the non-oriented receptive fields have oncenter or off-center organization. The other non-oriented receptive fields have on-off center responses and, as shown by Mangini and Pearlman (1980), can be further categorized by receptive field size and rates of spontaneous activity into two subclasses, one of which they referred to as large field, non-oriented (LFNO) cells. Mangini and Pearlman's (1980) analysis of receptive field properties as a function of laminar position demonstrated that LFNO cells were located in layer V. They demonstrated further that horseradish peroxidase injected into the superior colliculus labeled the large pyramidal neurons in layer $\mathrm{V}$. Their preliminary evidence that some LFNO cells could be activated antidromically by collicular stimulation has been confirmed and extended by the present study; all of the neurons of area 17 in the normal mouse that we isolated by collicular stimulation had receptive field properties that would place them in the LFNO category, and all were located in layer V. Corticotectal cells in area 17 of the cat and monkey are also located in layer V (Lund et al., 1979) and have many receptive field characteristics that are similar to those of CT cells in the mouse. In both cat (Palmer and Rosenquist, 1974) and monkey (Finlay et al., 1976), CT cells in area 17 have large receptive fields and high rates of spontaneous activity. In the cat, they have broad velocity sensitivity curves and very little spatial summation (Palmer and Rosenquist, 1974); these properties have not been examined in the monkey. The major differences between the CT cells in the visual cortex of the mouse and those in the monkey and the cat lie in their orientation and direction selectivity. Corticotectal cells in monkey and cat are less orientation selective than other cortical neurons, while CT cells in the mouse are nonoriented. Some CT cells in the cat and monkey are directionally selective; none are in the mouse.

Corticotectal cells thus constitute a class of neurons 
that are similar in laminar position and receptive field characteristics in the several mammals that have been analyzed. They have receptive field properties that distinguish them from other classes of cortical neurons and can be identified by antidromic activation during physiological recording; they are restricted to a single lamina in the normal mouse but are abnormally positioned in the reeler mutant.

Laminar position as a determinant of neuronal interconnections. We have observed that the receptive field properties of corticotectal cells in the visual cortex of the reeler mutant are, with the possible exception of field size, remarkably similar to those of CT cells in normal mice. From this observation, we conclude that the interneuronal connections required for these receptive field properties have been made correctly despite the profound disruption of the cortical lamination pattern that occurs in the reeler mutation.

If scveral stages of processing occur within the cortex prior to the CT cells, then our results suggest that normal connections have been made at the earlier stages in reeler cortex as well. The evidence on this point comes from three sources. First, some layer V cells in the visual cortex of the rat receive direct thalamic input on their apical dendrites (Peters et al., 1979), suggesting that the receptive field properties of CT cells may be produced, in part, by direct thalamic input. In contrast, current source density analyses of the visual cortex in both cat (Mitzdorf and Singer, 1978) and monkey (Mitzdorf and Singer, 1979) have shown that layer V cells are primarily activated by thalamic input through a di- or tri-synaptic pathway in the cortex, implying that significant processing occurs in the cortex prior to the CT cells. In addition, Gilbert and Wiesel (1979) have proposed, based on morphological studies of functionally identified neurons in the cat cortex, that information from the lateral geniculate nucleus passes through layer IV cells to layers II and III cells before reaching the neurons of layer $V$. Therefore, while thalamic input may contribute directly to the receptive field properties of $\mathrm{CT}$ cells to some extent, it is likely that a significant part of CT cell input is derived from other cortical neurons. If that is correct, then our demonstration that there are no significant differences between the CT cells of normal and reeler mice implies that connections within the cortex that precede CT cells in the flow of information are also being properly made.

The group of CT cells in reeler visual cortex with very large receptive fields constitutes the main evidence that the abnormality in cell position in reeler cortex produces some abnormality in connectional patterns. In the only other physiological study of the neocortex of reeler reported to date, Drager (1975b, 1977) observed that all of the receptive field types found in the visual cortex of the normal mouse were also present in the cortex of reeler. Drager also commented briefly on an abnormality in the receptive fields of some cells in the reeler visual cortex. These cells had extremely large receptive fields, and many, but not all, were superficially located. Since Drager (1975a) did not delineate a class of cells in the cortex of the normal mouse that corresponds to the large field, non-oriented cells described by Mangini and Pearlman (1980), it is not clear whether these cells correspond to the entire group of CT cells that we have studied or just to the subgroup of CT cells in reeler that have very large receptive fields. Alternatively, there may be a special class of cells with very large fields, distinct from CT cells, in the visual cortex of the reeler that we would have missed because we only analyzed cells that were antidromically activated by collicular stimulation.

Our results also permit certain conclusions regarding the topographic arrangement of the efferent connections of CT cells. The observation that a CT cell with a receptive field in a particular part of the visual field is activated by electrical stimulation of that portion of the colliculus that has its multi-unit receptive field in the same part of the visual field implies that CT cells of the retinotopically normal area 17 (P. A. Simmons, V. Lemmon, and A. L. Pearlman, manuscript in preparation) are making their collicular connections in approximately normal retinotopic fashion. This apparently normal topographic arrangement of axon projections to a subcortical structure from the reeler cortex is analogous to the results of anatomical studies of callosal projections by Caviness (1976b) and suggests that the laminar organization of the cortex does not play a crucial role in determining the ability of cortical efferents to make topographically ordered connections.

Our study provides physiological confirmation for the suggestions of Caviness and his colleagues (1977), based on neuroanatomical evidence, that the developmental mechanisms which govern the formation of connections in the cerebral cortex do not depend on the position of the target cells but instead may rely on specific cellular affinities between afferent axons and target cells. Studies of the reeler hippocampus (Bliss and Chung, 1974; Stanfield and Cowan, 1979a, b; Stanfield et al., 1979) have produced similar results; malpositioned pyramidal cells appear to receive their proper inputs, although the segregation of certain afferents to specific portions of the cell surface is abnormal. Similarly, in the cerebellum of reeler, displaced Purkinje cells still receive input from climbing fibers (Mariani et al., 1977), although the number of climbing fibers per Purkinje cell is abnormal. While normal synapse formation in the cortex probably depends on specific cellular affinities between axons and target cells, it may be, as suggested by Pinto-Lord and Caviness (1979), that target cells play an active role in synapse formation by sending cellular processes short distances to interact with afferent axons.

Even though our neurophysiological evidence and the wide variety of neuroanatomical evidence previously cited would suggest that laminar position plays a minor role in determining cortical interneuronal connections, there are several reasons to avoid discounting such a role completely and to avoid generalizing this result to other neuronal classes or to other locations affected by the mutation. In the first place, although $\mathrm{CT}$ cells were selected as the appropriate neurons for this analysis because of their distinctive receptive field properties, their location in a single lamina and their easily accessible projection axons, the receptive field properties of CT cells are not highly specific. It is possible that cells with fields that require more defined stimuli, such as the oriented simple and complex cells of layers II and III, 
might also need to receive their connections in a more precise manner in order to function properly and therefore might be more significantly affected by positional abnormalities. Studies are currently underway in our laboratory to test this possibility. Secondly, although the most obvious effect of the reeler mutation is to alter the lamination of particular cortical structures, there is no indication as to how the mutation produces this effect and no direct evidence that the effect is primary rather than the consequence of something more remote. Although conclusions based on the reeler model appear to be quite compelling at present, validation of these conclusions must await a better understanding of the way cortical lamination is formed; an analysis of how lamination is disrupted by the reeler mutation may well contribute to such an understanding. Finally, lamination is such a prominent and ubiquitous feature of mammalian neocortex that it is difficult to conclude that it has no role whatever in determining cortical connections. It is possible, of course, that the laminar arrangement of neurons somehow facilitates the appropriate connections but is not fully necessary for their establishment. By analogy, many considerations other than functional role in the circuit dictate the placement of particular elements in a complex piece of electronic equipment; convenience in wiring and optimal packing arrangements are two that come readily to mind. A functioning circuit can be constructed without taking these factors into account, albeit less efficiently. Whether such considerations are important in forming the structure of the neocortex is a matter for speculation at present; our neurophysiological evidence and that provided by the neuroanatomical studies of the reeler suggest that factors other than neuronal position are primary in determining cell-to-cell interconnections in the neocortex and that, for the most part, such factors are able to overcome the difficulties imposed by the anomalies in neocortical lamination that exist in the reeler neocortex.

\section{References}

Angevine J. B., Jr., and R. L. Sidman (1961) Autoradiographic study of cell migration during histogenesis of cerebral cortex in the mouse. Nature 192: 766-768.

Bliss, T. V., and S.- H. Chung (1974) An electrophysiological study of the hippocampus of the 'reeler' mutant mouse. Nature 252: 153-155.

Brodmann, K. (1903) Beitrage zur histologische lokalisation der grosshernrinde. Zweite Mitteilung: der calcarinatypus. J. Psychol. Neurol. Lpz. 2: 79-159.

Camarada, R., and G. Rizzolatti (1976) Receptive fields of cells in the superficial layers of the cat's area 17. Exp. Brain Res. 24: 423-427.

Campbell, A. W. (1903) Histological studies on cerebral localization. Proc. R. Soc. (Lond.) (Biol.) 72: 488-492.

Carey, R. G., D. Fitzpatrick, and I. T. Diamond (1979) Layer 1 of striate cortex of Tupaia glis and Galago senegalensis: Projections from thalamus and claustrum revealed by retrograde transport of horseradish peroxidase. J. Comp. Neurol. 186: 393-438.

Caviness, V. S., Jr. (1975) Structure of visual cortex of the reeler mutant mouse: A Golgi analysis. Soc. Neurosci. Abstr. 1: 101.

Caviness, V.S., Jr. (1976a) Patterns of cell and fiber distribution in the neocortex of the reeler mutant mouse. J. Comp. Neurol. 170: $435-448$.
Caviness, V. S., Jr. (1976b) Interhemispheric neocortical connections of the corpus callosum in the reeler mutant mouse: A study based on anterograde and retrograde methods. $\mathrm{J}$. Comp. Neurol. 170: 449-460.

Caviness, V. S., Jr. (1977) The reeler mutant mouse: A genetic experiment in developing mammalian cortex. Neurosci. Symp. 2: 27-46.

Caviness, V. S., Jr., and R. L. Sidman (1973) Time of origin of corresponding cell classes in the cerebral cortex of normal and reeler mutant mice: An autoradiographic analysis. J. Comp. Neurol. 148: 141-152.

Drager, U. C. (1975a) Receptive fields of single cells and topography in mouse visual cortex. J. Comp. Neurol. 160: 269-290.

Drager, U. C. (1975b) Physiologic properties of cells in the primary visual cortex of the reeler mutant mouse. Soc. Neurosci. Alustr. 1: 102.

Drager, U. C. (1977) Reeler mutant mice: Physiology in primary visual cortex. In Function and Formation of Neural Systems: Report of the Dahlem Workshop on Function and Formation of Neural Systems, Berlin, 1977, G. S. Stent, ed., pp. 274-276, Dahlem Konferenzen, Berlin.

Drager, U. C., and D. H. Hubel (1975) Responses to visual stimulation and relationship between visual, auditory, and somatosensory inputs in mouse superior colliculus. J. Neurophysiol. 38: 690-713.

Ferster, D., and S. LeVay (1978) The axonal arborizations of lateral geniculate neurons in the striate cortex of the cat. $J$. Comp. Neurol. 182: 923-944.

Finlay, B. L., P. H. Schiller, and S. F. Volman (1976) Quantitative studies of single-cell properties in monkey striate cortex. IV. Corticotectal cells. J. Neurophysiol. 39: 1352-1361.

Frost, D. O., and V. S. Caviness, Jr. (1974) Patterns of thalamic projections to the neocortex of normal and reeler mutant mice. Neurosci. Abstr. 4: 217.

Gilbert, C. D. (1977) Laminar differences in receptive field properties of cells in cat primary visual cortex. J. Physiol. (Lond.) 268: 391-421.

Gilbert, C. D., and J. P. Kelly (1975) The projections of cells in different layers of the cat's visual cortex. J. Comp. Neurol. 163: 81-106.

Gilbert, C. D., and T. Wiesel (1979) Morphology and intracortical projections of functionally characterized neurons in the cat visual cortex. Nature 280: 120-125.

Hollander, H. (1974) On the origin of the corticotectal projection in the cat. Exp. Brain Res. 21: 433-439.

Hubel, D. H., and T. N. Wiesel (1962) Receptive fields, binocular interaction and functional architecture in cat's visual cortex. J. Physiol. (Lond.) 160: 215-243.

Hubel, D. H., and T. N. Wiesel (1968) Receptive fields and functional architecture of monkey striate cortex. J. Physiol (Lond.) 195: 215-243.

Hubel, D. H., and T. N. Wiesel (1972) Laminar and columnar distribution of geniculocortical fibers in the macaque monkey. J. Comp. Neurol, 146: 421-450.

Kelly, J. P., and D. C. Van Essen (1974) Cell structure and function in the visual cortex of the cat. J. Physiol (Lond.) 238: $515-547$.

Lemmon, V., and A. L. Pearlman (1979a) Receptive field properties of corticotectal cells in visual cortex of normal and reeler mutant mice. ARVO Program Abstracts. Invest. Ophthalmol. Vis. Sci. 18 (suppl.): 229-230.

Lemmon, V., and A. L. Pearlman (1979b) Does cell position determine receptive field properties of neurons in the mouse visual cortex? Soc. Neurosci. Abstr. 5: 168.

LeVay, S., and D. Gilbert (1976) Laminar patterns of geniculocortical projection in the cat. Brain Res. 113: 1-19.

Leventhal, A. G. (1979) Evidence that different classes of relay cells of the cat's lateral geniculate nucleus terminate in dif- 
ferent layers of the striate cortex. Exp. Brain Res. 37: 349372.

Leventhal, A. G., and H. V. B. Hirsch (1978) Receptive field properties of neurons in different laminae of visual cortex of the cat. J. Neurophysiol. 41: 948-962.

Lund, J. S., G. H. Henry, C. L. MacQueen, and A. R. Harvey (1979) Anatomical organization of the primary visual cortex (area 17) of the cat. A comparison with area 17 of the macaque monkey. J. Comp. Neurol. 184: 599-618.

Maffei, L., and A. Fiorentini (1977) Spatial frequency rows in the striate visual cortex. Vision Res. 17: 257-264.

Mangini, N. J., and A. L. Pearlman (1980) The laminar distribution of receptive field properties in the primary visual cortex of the mouse, Mus musculus. J. Comp. Neurol. 193: 203-222.

Mariani, J., F. Crepel, K. Mikoshiba, J. P. Changeux, and C. Sotelo (1977) Anatomical, physiological and biochemical studies of the cerebellum from reeler mutant mouse. Phil. Trans. R. Soc. Lond. B. Biol. Sci. 281: 1-28.

Mitzdorf, U., and W. Singer (1978) Prominent excitatory pathways in the cat visual cortex (A 17 and A 18): A current source density analysis of electrically evoked potentials. Exp. Brain Res. 33: 371-394.

Mitzdorf, U., and W. Singer (1979) Excitatory synaptic ensemble properties in the visual cortex of the macaque monkey: $A$ current source density analysis of electrically evoked potentials. J. Comp. Neurol. 187: 71-84.

Movshon, J. A. (1975) The velocity tuning of single units in cat striate cortex. J. Physiol. (Lond.) 249: 445-468.

Palmer, L. A., and A. C. Rosenquist (1974) Visual receptive fields of single striate cortical units projecting to the superior colliculus in the cat. Brain Res. 67: 27-42.

Peters, A., C. C. Proskauer, M. L. Feldman, and L. Kimerer (1979) The projection of the lateral geniculate nucleus to area 17 of the rat cerebral cortex. V. Degenerating axon terminals synapsing with Golgi impregnated neurons. J. Neurocytol. 8: 331-357.

Pinto-Lord, M. C., and V. S. Caviness, Jr. (1979) Determinants of cell shape and orientation: A comparative Golgi analysis of cell-axon interrelationships in the developing neocortex of normal and reeler mice. J. Comp. Neurol. 187: 49-70.

Rakic, P. (1974) Neurons in the rhesus monkey visual cortex: Systematic relation between time of origin and eventual disposition. Science 183: 425-427.

Rakic, P. (1976) Synaptic specificity in the cerebellar cortex: Study of anomalous circuits induced by single gene mutations in mice. Cold Spring Harbor Symp. Quant. Biol. 40: 333-346.

Schiller, P. H., B.L. Finlay, and S. F. Volman (1976) Quantitative studies of single-cell properties in monkey striate cortex. II. Orientation specificity and ocular dominance. J. Neurophysiol. 39: 1320-1333.

Stanfield, B. B., and W. M. Cowan (1979a) The morphology of the hippocampus and dentate gyrus in normal and reeler mice. J. Comp. Neurol. 185: 393-422.

Stanfield, B. B., and W. M. Cowan (1979b) The development of the hippocampus and dentate gyrus in normal and reeler mice. J. Comp. Neurol. 185: 423-460.

Stanfield, B. B., V. S. Caviness, Jr., and W. M. Cowan (1979) The organization of certain afferents to the hippocampus and dentate gyrus in normal and reeler mice. J. Comp. Neurol. 185: 461-484.

Steindler, D. A., and S. A. Colwell (1976) Reeler mutant mouse: Maintenance of appropriate connections in the cerebral cortex and thalamus. Brain Res. 105: 386-393.

Tigges, J., M. Tigges, and A. A. Perachio (1977) Complementary laminar terminations of afferents to area 17 originating in area 18 and in the lateral geniculate nucleus in squirrel monkey. J. Comp. Neurol. 176: 87-100.

Toyama, K., T. Matsunami, T. Ohno, and S. Tokashiki (1974) An intracellular study of neuronal organization in visual cortex. Exp. Brain Res. 21: 45-66.

Vogt, O. (1903) Zur anatomischen gliederung des cortex cerebri. J. Psychol. Neurol. Lpz. 2: 160-180.

Wagor, E., N. J. Mangini, and A. L. Pearlman (1980) Retinotopic organization of striate and extrastriate visual cortex in the mouse, Mus musculus. J. Comp. Neurol. 193: 187-202. 